\title{
PENGARUH MODEL SAVI BERBANTUAN SOFTWARE PENGENDALI CLIENT TERHADAP TINGKAT KEDISIPLINAN DAN HASIL BELAJAR MATEMATIKA
}

\author{
Stephanus Lukito Cahyo Purnomo*, Dedi Kuswandi, Henry Praherdhiono. \\ Teknologi Pembelajaran, Fakultas Ilmu Pendidikan, Universitas Negeri Malang
}

\section{Edcomtech}

Jurnal Kajian Teknologi Pendidikan

Volume 6, No 2, Oktober 2021

243-253

DOI: $10.17977 /$ um039v6i12021p243

Submitted 04-09-2020

Accepted 08-04-2021

\section{Corresponding Author*}

Stephanus Lukito Cahyo P. Universitas Negeri Malang Jl. Semarang No.5, Sumbersari, Kec. Lowokwaru, Kota Malang, Jawa Timur 65145, Indonesia Email: capenxchayo@gmail.com

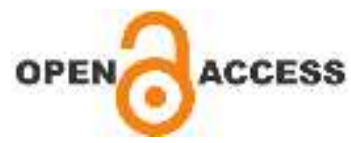

\begin{abstract}
Abstrak
Penelitian ini bertujuan untuk mengetahui pengaruh model pembelajaran SAVI (Somatic, Auditory, Visualization, Intellectualy) berbantuan software pengendali client terhadap tingkat kedisiplinan dan hasil belajar Matematika pada siswa kelas V. Desain penelitian ini menggunakan eksperimental semu (quasi experiment) dengan bentuk nonequivalent control group design. Teknik pengumpulan data dengan metode observasi, wawancara dan tes. Hasil penelitian menunjukkan model pembelajaran SAVI berbantuan software pengendali client berpengaruh terhadap tingkat kedisiplinan siswa pada mata pelajaran Matematika. Namun, tidak ditemukan adanya perbedaan signifikan antara hasil belajar matematika antara siswa pada kelompok kontrol dan perlakuan. Kesimpulan dari penelitian ini adalah model pembelajaran SAVI berbantuan software pengendali client mempunyai pengaruh yang signifikan terhadap kedisiplinan siswa. Rekomendasi untuk penelitian selanjutnya adalah model pembelajaran SAVI dapat dikombinasikan dengan media yang lain. Penelitian ini tidak berlangsung secara sempurna dikarenakan pandemi Covid-19.
\end{abstract}

Kata Kunci: Model SAVI, Software Pengendali Client, Tingkat Kedisiplinan, dan Hasil Belajar.

\footnotetext{
Abstract

This research aims to determine the effect of SAVI (Somatic, Auditory, Visualization, Intellectually) learning model assisted by client control software on the level of discipline and mathematics learning outcomes in fifth grade. This research design using quasi experimental (quasi experiment) with the form of the nonequivalent control group design. Data collection techniques using observation, interview and test methods. The results showed that the SAVI learning model assisted by client control software had an influence on the level of student discipline in mathematics, but there was no significant difference in student learning outcomes. The conclusion of this study is the SAVI learning model assisted by client controller software has a significant effect on the level of student discipline. The recommendation for further research is that the SAVI learning model can be combined with other media. This research did not take place perfectly due to the Covid-19 pandemic.

Keywords: SAVI Model, Client Control Software, Discipline Level, and Learning Outcomes.
} 


\section{LATAR BELAKANG}

\begin{tabular}{lll}
\multicolumn{2}{c}{ Meningkatnya } & penggunaan \\
Computer-Aided & Design (CAD) & dalam \\
pembelajaran & terutama & dalam
\end{tabular}
pemanfaatan teknologi komputer serta komunikasi di SDK Santa Maria II Malang, hal ini menunjukkan hasil positif. Menurut Abdulhak (2015), definisi teknologi yaitu proses dan produk yang dikembangkan dan digunakan untuk memudahkan dan meningkatkan kinerja serta nilai tambah. Dalam proses pengembangan tersebut, keterlibatan guru secara aktif menjadi salah satu faktor yang menentukan kesesuaian antara kebutuhan peserta didik dan karakteristik teknologi yang dikembangkan (Matuk et al., 2015). Hal ini perlu dicermati oleh para guru dalam mengaktualisasikan kompetensinya secara profesional. Rücker \& Pinkwart (2016) mengatakan komputer telah lama menjadi alat penting untuk pengajaran dan pembelajaran di berbagai mata pelajaran lainnya. Akhtar et al. (2017) menambahkan bahwa pembelajaran Computer-Aided Design (CAD) berbasis laboratorium berhasil memantau partisipasi siswa di kelas.

Perkembangan teknologi dalam bidang pendidikan melahirkan berbagai inovasi pembelajaran. Dalam praktik-nya inovasi pembelajaran dapat dikembangkan dalam bentuk media, bahan, metode, dan bentuk evaluasi pembelajaran (Praherdhiono et al., 2019). Salah satu inovasi yang penting yakni inovasi model pembelajaran. Sebagaimana yang menjadi fokus dalam penelitian ini.

Pengembangan proses pembelajaran yang belum optimal menjadi salah satu masalah yang dihadapi di dunia pendidikan saat ini. Kondisi guru saat ini menjadi salah satu faktor dalam mengembangkan pembelajaran di kelas. Guru masih lemah dalam membuat perencanaan proses pembelajaran dengan memanfaatkan teknologi di kelasnya. Akan tetapi ada guru yang membuat perencanaan matang dalam melaksanakan pembelajarannya, meman-faatkan teknologi dan memperhati-kan taraf perkembangan belajar siswa. Guru yang dapat mengembangkan proses pembelajaran dengan mempertim-bangkan berbagai faktor diyakini akan menghasilkan kualitas lulusan yang baik. Di sisi lain, ternyata pada kenyataan masih banyak guru yang kurang mampu mengembangkan proses pembelajaran. Praktik-praktik pembelajaran cenderung lebih menonjolkan aktivitas guru dan terbatas pada menghafal saja. Pada akhirnya, bukan hanya teknologi yang mendorong perubahan di kelas. Menurut Fabian et al. (2018), kemampuan teknis, karakteristik siswa dan desain pembelajaran semuanya dipandang sebagai tanggung jawab guru dan akan bermanfaat jika guru dilatih untuk menggunakan teknologi baru.

Berdasarkan temuan di atas bahwa proses pembelajaran masih terbatas hafalan semata dan terfokus pada guru, padahal kurikulum yang digunakan adalah kurikulum 2013 di mana dalam proses pembelajarannya dibuat untuk lebih mengaktifkan siswa. Dari sekian banyak model pembelajaran, peneliti mencoba mengimplementasikan model pembelajaran SAVI. Model pembelajaran ini dipilih karena secara umum model ini dapat mengajak siswa untuk aktif dalam menggunakan kemampuan gerak, audio, visual serta kecerdasan yang dimiliki siswa. Model pembelajaran SAVI (Somatic, Auditory, Visualization, Intellectualy) adalah model pembelajaran yang dapat mengaktifkan siswa dalam proses pembelajarannya. Model pembelajaran SAVI menuntut semua siswa harus bisa memanfaatkan alat indera mereka untuk menunjang proses pembelajaran. Ada empat komponen dalam model pembelajaran SAVI antara lain: Somatic (belajar dengan melakukan dan bergerak sehingga timbul aktivitas yang positif dalam pembelajaran), Auditory (belajar sambil berbicara dan mendengarkan), Visualization (belajar sambil menga-mati gambar atau video yang 
menunjang terlaksananya pembelajaran), Intellectually (meme-cahkan masalah dengan berpikir baik secara individu maupun kelompok) (Shoimin, 2013)

Sarnoko et al. (2016) mengatakan bahwa pendekatan SAVI menimbulkan konsep belajar berbasis aktivitas. Gaol (2014) juga menyatakan model pembelajaran SAVI dapat menambah pemahaman, perhatian serta motivasi sehingga dapat meningkatkan prestasi belajar. Penelitian yang dilakukan oleh Cemara \& Sudana (2019) juga mendapatkan hasil di mana model SAVI mempunyai daya dukung terhadap kreativitas serta penguasaan kognitif mata pelajaran IPA. Hasil penelitiannya mengungkapkan bahwa penggunaan model SAVI juga berpengaruh terhadap prestasi dan keaktifan siswa sehingga disarankan untuk dijadikan alternatif model pembelajaran pilihan untuk dipakai terutama bidang studi Matematika.

Menurut Yaumi (2018), disiplin merupakan perilaku patuh serta tertib terhadap ketentuan atau peraturan. Hasil penilaian sikap dan wawancara terhadap guru kelas $\mathrm{V}$, terdapat beberapa siswa yang ternyata belum memiliki perilaku disiplin dalam mengikuti pembelajaran di kelas terlebih ketika berada dalam laboratorium komputer. Ditemukan juga bahwa siswa yang belum memiliki perilaku disiplin yang tinggi rata-rata juga belum memiliki hasil belajar yang baik pula. Perbedaan yang mendasar dari penelitian sebelumnya terletak pada media pembelajaran yang dikombinasikan dengan model pembelajaran SAVI dimana media ini digunakan untuk mengontrol tingkat kedisiplinan siswa saat pembelajaran Matematika di laboratorium komputer.

Pembelajaran Matematika yang dilaksanakan ini memanfaatkan penggunaan teknologi yang sudah dipunyai oleh SDK Santa Maria II Malang. Hasil penelitian dari Carrasco \& Torrecilla
(2012) menyatakan bahwa penggunaan komputer berpengaruh positif pada kinerja yang dicapai oleh anak kelas enam di Amerika Latin. Salah satu masalah yang terjadi pada proses pembelajaran di laboratorium komputer, adalah ketika guru melakukan pemantauan kinerja siswa pada komputer siswa masing-masing. Hal ini membutuhkan waktu yang lama terlebih jika jumlah siswa dalam satu kelasnya mencapai 30 orang atau lebih. Maka diperlukan cara untuk mengontrol komputer dari jarak jauh. Viennet dan Petrucci (2014) mengatakan Universitas Perancis mempunyai perangkat lunak ScoDoc di mana sistem ini dirancang untuk mengumpulkan semua informasi yang tersedia mengenai siswa seperti data pribadi, hasil tes, ketekunan siswa. Smart Lab digunakan Sohail et al. (2011) untuk melakukan sesi lab dan latihan kelas yang interaktif, efisien, terkontrol dan terpantau secara penuh oleh guru. Salah satu alternatif yang lain yaitu dengan menggunakan software pengendali client. Untuk penelitian ini, software yang dipakai adalah Classroom Spy Pro. Tool ini mempunyai beberapa keuntungan antara lain: administrator server (guru) dapat memantau secara real time komputer client (siswa) sehingga proses pembelajaran bisa terkontrol jarak jauh tanpa harus datang ke meja komputer client satu per satu. Memantau komputer di laboratorium sangat penting dilakukan. Harron et al. (2017) dan Salvi et al. (2019) mengatakan sistem pemantauan komputer ini bermanfaat untuk menambah tingkat akses, keamanan serta dapat memantau setiap siswa dan menilai kemajuan proses pembelajaran dari pengguna komputer yang berada dalam satu jaringan LAN.

Menurut hasil penilaian tengah semester I mata pelajaran Matematika kelas V tahun ajaran 2019/2020 masih terdapat beberapa siswa yang tidak tuntas dalam pencapaian ketuntasan belajar minimal mata pelajaran Matematika. Berdasarkan wawancara dengan guru kelas ditemukan bahwa pemahaman akan soal Matematika sangat lemah, terlihat dari hasil kerja siswa yang sering mengalami kesalahan diantaranya 
(1) Siswa kurang terampil dalam mendapatkan informasi soal, (2) Kesulitan menemukan proses cara mengerjakannya, (3) Menentukan hasil akhir yang benar. Dalam proses pembelajarannya kemampuan berpikir siswa masih kurang porsinya dalam membangun karakter atau potensi mereka. Maka proses pembelajaran perlu diarahkan agar terbentuk pribadi yang kreatif dan inovatif. Schoenfeld (2013) mengatakan memberikan kesempatan semua siswa untuk berpartisipasi secara bermakna dalam kegiatan kelas terlebih mata pelajaran Matematika adalah hal yang sangat penting. Atas dasar itu penulis mencoba mengimplementasikan model pembela-jaran SAVI berbantuan software pengendali client untuk meningkatkan kedisiplinan dan menguasai kemampuan dalam pengolahan data secara efektif dan efisien.

\section{METODE}

\section{Desain Penelitian}

Dalam melaksanakan proses penelitian diperlukan pedoman yaitu desain penelitian. Desain penelitian ini menggunakan eksperimental semu (quasi experiment) dengan bentuk desain kelompok kontrol nonequivalent. Dalam penelitian ini kedua kelompok baik kelompok eksperimen atau kelompok kontrol tidak ada yang dipilih secara acak, dengan kemampuan yang relatif sama serta banyaknya jumlah siswa yang sama. Adapun kelas eksperimen dan kelas kontrol dilakukan ujian 2 kali yaitu pretest dan posttest. Dua kelompok tersebut juga mendapatkan tujuan pembelajaran, materi serta soal yang sama. Tetapi dalam proses pembelajaran, kedua kelompok kelas menggunakan model SAVI, tetapi yang menjadi pembeda adalah kelas eksperimen menggunakan bantuan software pengendali client dan kelas kontrol tidak menggunakan bantuan software pengendali client. Desain penelitian dapat dilihat pada tabel 1 .
Tabel 1. Desain Penelitian

\begin{tabular}{llll}
\hline Kelas & Pretest & Perlakuan & Posttest \\
\hline $\begin{array}{l}\text { Eksperimen } \\
-5 \mathrm{~A}\end{array}$ & $\mathrm{O} 1$ & $\mathrm{X} 1$ & $\mathrm{O} 2$ \\
$\begin{array}{l}\text { Kontrol - } \\
\text { 5B }\end{array}$ & $\mathrm{O} 3$ & $\mathrm{X} 2$ & $\mathrm{O} 4$ \\
\hline $\mathrm{X} 1=$ & & \\
\hline
\end{tabular}

$\mathrm{X} 1=$ Model Pembelajaran SAVI (Somatic, Auditory, Visualization, Intellectualy) Berbantuan Software Pengendali Client,

X2 = Model Pembelajaran SAVI (Somatic, Auditory, Visualization, Intellectualy), tabel dimodifikasi dari Sugiyono (2015).

Menurut Mangesti (2016) kedisiplinan siswa dapat diukur melalui observasi aktivitas siswa. Oleh karena itu selama proses pembelajaran, guru kelas beserta kolaborator mengamati aktivitas siswa berdasarkan tahapan dalam model pembelajaran SAVI. Hasil dari observasi tersebut dijadikan acuan untuk menentukan tingkat kedisiplinan siswa. Selain itu, hasil pretest dan posttest dari kedua kelas tersebut dicari rata-rata untuk dibandingkan antara keduanya. Jika terdapat perbedaan yang signifikan dari kedua kelas tersebut, maka dapat dinyatakan bahwa model pembelajaran SAVI berbantuan software pengendali client yang diterapkan pada kelas eksperimen berpengaruh.

\section{Instrumen Penelitian}

Uji Validitas Instrumen. Instrumen penelitian yang akan divalidasi berupa silabus, RPP, LKS, soal tes pemahaman konsep dan lembar observasi. Instrumen-instrumen tersebut akan divalidasi oleh dosen ahli. Kemudian hasil validasi akan dihitung persentasenya. Adapun kriteria validasi instrumen dapat dilihat pada tabel 2.

Tabel 2. Kriteria Validasi Instrumen

\begin{tabular}{ll}
\hline Persentase (\%) & Kriteria \\
\hline $75 \% \leq$ SR $\leq 100 \%$ & Valid tanpa revisi \\
$50 \% \leq$ SR $\leq 75 \%$ & Belum valid dengan \\
& sedikit revisi \\
$25 \% \leq$ SR $\leq 50 \%$ & Belum valid dengan \\
& banyak revisi \\
SR $\leq 25 \%$ & Tidak valid \\
\hline
\end{tabular}

Sumber: Kusaeri (2012)

Hasil validasi oleh validator ditunjukkan pada tabel 3. 
Tabel 3. Data Hasil Validasi Perangkat Pembelajaran dan Instrumen Penelitian

\begin{tabular}{|c|c|c|c|}
\hline Validasi & Skor & Persentase & Kriteria \\
\hline Silabus & 46 & $77 \%$ & $\begin{array}{l}\text { Valid } \\
\text { tanpa } \\
\text { revisi }\end{array}$ \\
\hline RPP & 50 & $83 \%$ & $\begin{array}{l}\text { Valid } \\
\text { tanpa } \\
\text { revisi }\end{array}$ \\
\hline LKS & 47 & $85 \%$ & $\begin{array}{l}\text { Valid } \\
\text { tanpa } \\
\text { revisi }\end{array}$ \\
\hline $\begin{array}{l}\text { Lembar } \\
\text { Observasi }\end{array}$ & 27 & $77 \%$ & $\begin{array}{l}\text { Valid } \\
\text { tanpa } \\
\text { revisi }\end{array}$ \\
\hline Soal Tes & 69 & $86 \%$ & $\begin{array}{l}\text { Valid } \\
\text { tanpa } \\
\text { revisi }\end{array}$ \\
\hline
\end{tabular}

Berdasarkan data tabel 3 maka

kesimpulannya adalah instrumen pembelajaran dan perangkat pembelajaran mendapatkan kriteria valid tanpa revisi. Peneliti memperhatikan hasil validasi yang diberikan oleh validator. Dengan adanya beberapa saran yang diberikan agar peneliti menyempurnakan instrumen penelitian dan perangkat pembelajaran. Instrumen penelitian dan perangkat pembelajaran diperbaiki oleh peneliti sesuai saran dari validator.

\section{Subjek Penelitian}

Yang menjadi subjek penelitian adalah siswa kelas V SDK Santa Maria II Malang tahun ajaran 2019/2020. Jumlah subjek penelitian adalah 66 siswa. Subjek tersebut terbagi menjadi dua, yaitu kelas VA sebagai kelas eksperimen yang akan diberikan perlakuan menggunakan model pembelajaran SAVI berbantuan software pengendali client dengan jumlah 33 siswa dan kelas VB sebagai kelas kontrol yang akan diberikan perlakuan menggunakan model pembelajaran SAVI dengan jumlah 33 siswa.

\section{Tempat dan Waktu Penelitian}

Penelitian dilakukan di SDK Santa Maria II dengan alamat Jalan Panderman nomor 7 Kota Malang. Peneliti melaksanakan enam kali pertemuan pembelajaran. Alokasi waktu tiap pertemuan adalah 2 x 35 menit. Penelitian dilaksanakan pada Bulan Februari 2020 - Maret 2020.

\section{Analisis Data}

Uji Independent $T$ Test digunakan untuk mengetahui pengaruh penggunaan software pengendali client dalam model pembelajaran SAVI terhadap tingkat kedisiplinan siswa. Analisis data tingkat kedisiplinan siswa berupa data kuantitatif, yang didasarkan pada lembar observasi tingkat kedisiplinan siswa. Observasi dilakukan untuk melihat tingkat kedisiplinan siswa dalam setiap pertemuan pembelajaran selama proses pembelajaran berlangsung. Tingkat kedisiplinan siswa diamati melalui lembar observasi meliputi: ketaatan terhadap tata tertib, ketaatan terhadap kegiatan belajar, dan ketaatan dalam mengerjakan tugas. Observasi tingkat kedisiplinan siswa dilakukan selama proses pembelajaran berlangsung. Yang berperan sebagai observer 1 (01) adalah guru kelas VA dan VB, observer 2 (O2) adalah peneliti sendiri, observer 3 (O3) adalah kepala sekolah dan guru sejawat.

Uji Anova (analysis of varian) Two Way digunakan untuk mengetahui pengaruh penggunaan software pengendali client dalam model pembelajaran SAVI terhadap hasil belajar siswa. Pengujian ini dilakukan karena peneliti akan menguji hipotesis komparatif rata-rata dari 2 sampel kelas yang memiliki 2 kategori. Pengujian ini dilakukan untuk mengetahui selisih gain score antara pretest dan posttest, sehingga dapat digunakan menyimpulkan hasil penelitian. Uji ini dilakukan pada subjek penelitian sebelum dan sesudah proses perlakuan. Melalui tes pemahaman konsep siswa diperoleh data kuantitatif berupa skor pretest dan posttest. Dari data tersebut diketahui hasil belajar ranah kognitif Matematika siswa yang diajarkan menggunakan model pembelajaran SAVI berbantuan software pengendali client. Berdasarkan hal tersebut maka model pemebelajaran SAVI dapat mulai untuk diimplementasikan. 
HASIL

Hasil observasi tingkat kedisiplinan siswa digunakan sebagai dasar untuk melakukan Uji Independent T Test. Hasil tersebut dapat dilihat pada tabel 4 . Tabel 4 menunjukkan bahwa jumlah skor kelas kontrol adalah 228,60 sedangkan skor kelas eksperimen adalah 247,69. Rata-rata dari kedua menunjukkan skor 76,20 untuk kelas kontrol dan 82,56 untuk kelas eksperimen.

Uji Independent T Test digunakan untuk mengetahui pengaruh penggunaan software pengendali client dalam model pembelajaran SAVI terhadap tingkat kedisiplinan siswa. Hasil pengujian dapat dilihat pada tabel di bawah ini Dari data diperoleh dua nilai output yaitu Equal variances assumed dan Equal variances not assumed. Taraf sig. F adalah 0,191 yang artinya Ho diterima bahwa kedua populasi identik. Karena sig. $\mathrm{F}$ mempunyai keputusan Equal variances assumed maka t-test menggunakan Equal variances assumed. Terlihat bahwa nilai Sig. (2tailed) =0,000. Karena Sig, $<0,05$ dengan demikian menolak Ho atau menerima $\mathrm{Hi}$, sehingga kesimpulan yang didapat adalah terdapat perbedaan signifikan terhadap tingkat kedisiplinan belajar Matematika antara kedua kelompok kelas.

Tabel 4. Hasil observasi tingkat kedisiplinan siswa

\begin{tabular}{lcc}
\hline \multicolumn{1}{c}{$\begin{array}{c}\text { Aspek } \\
\text { Kedisiplinan }\end{array}$} & $\begin{array}{c}\text { Rata- } \\
\text { rata } \\
\text { Kelas } \\
\text { Kontrol }\end{array}$ & $\begin{array}{c}\text { Rata-rata } \\
\text { Kelas } \\
\text { Eksperimen }\end{array}$ \\
\hline $\begin{array}{l}\text { Ketaatan } \\
\text { terhadap tata } \\
\text { tertib }\end{array}$ & 76,85 & 82,78 \\
$\begin{array}{l}\text { Ketaatan } \\
\text { terhadap } \\
\text { kegiatan } \\
\text { belajar }\end{array}$ & 74,81 & 82,04 \\
$\begin{array}{l}\text { Ketaatan } \\
\text { mengerjakan }\end{array}$ & 76,94 & 82,87 \\
tugas & & \\
\multicolumn{1}{c}{ Jumlah } & 228,60 & 247,69 \\
$\quad$ Rata-rata & 76,20 & 82,56 \\
\hline
\end{tabular}

Uji ANOVA Two Way digunakan untuk mengetahui pengaruh penggunaan software pengendali client dalam model pembelajaran SAVI terhadap hasil belajar siswa. Sebelum melakukan uji ANOVA Two Way peneliti melakukan uji homogenitas menggunakan Levene's Test dengan hasil seperti pada tabel 6.

Berdasarkan output Levene's pada tabel 6 diperoleh nilai signifikansi (Sig.) adalah sebesar 0,246>0,05, maka dapat disimpulkan bahwa varian variabel hasil belajar adalah sama atau homogen.

Untuk selanjutnya peneliti melanjutkan pengujian Anova Two Way dengan hasil seperti pada tabel 7. Tabel 7 menunjukkan hasil analisi terhadap korelasi antar kelas baik dalam kelas control dan kelas ekspertimen. Analisis ini digunakan untuk mengetahui hubungan pada perlakuan penelitian.

Diketahui hasil pengujian hipotesis peneliti berdasarkan output source kelas di mana diperoleh nilai Sig. sebesar 0,572 >0,05, sehingga $\mathrm{Hi}$ ditolak dan menerima Ho. Dari hasil tersebut maka kesimpulan yang didapat adalah tidak ditemukan perbedaan yang signifikan terhadap hasil belajar Matematika antara kedua kelompok kelas.

Tabel 5. Independent Samples Test

\begin{tabular}{|c|c|c|c|c|}
\hline & \multicolumn{2}{|c|}{$\begin{array}{l}\text { Levene's Test } \\
\text { for Equality } \\
\text { of Variances }\end{array}$} & \multirow{2}{*}{$\begin{array}{c}\text { t-test for } \\
\text { Equality } \\
\text { of Means } \\
\text { Sig. (2- } \\
\text { tailed) }\end{array}$} \\
\hline & & $\mathbf{F}$ & Sig. & \\
\hline \multirow[b]{2}{*}{ Hasil } & $\begin{array}{l}\text { Equal } \\
\text { variances } \\
\text { assumed }\end{array}$ & 191 & ,664 & , 000 \\
\hline & $\begin{array}{l}\text { Equal } \\
\text { variances } \\
\text { not } \\
\text { assumed }\end{array}$ & & & , 000 \\
\hline \multicolumn{5}{|c|}{$\begin{array}{c}\text { Tabel 6. Levene's Test of Equality of Error } \\
\text { Variances }^{\text {a }}\end{array}$} \\
\hline \multicolumn{5}{|c|}{ Dependent Variable: Hasil } \\
\hline & $\mathrm{F}$ & & df2 & Sig. \\
\hline & 401 & & 120 & ,246 \\
\hline
\end{tabular}

Tests the null hypothesis that the error variance of the dependent ariable is equal across groups.

a. Design: Intercept + Kelas + Jenis + Kelas * Jenis 
Tabel 7. Tests of Between-Subjects Effects

\begin{tabular}{lrr}
\hline \multicolumn{1}{c}{ Source } & $\begin{array}{c}\text { Type III Sum of } \\
\text { Squares }\end{array}$ & \multicolumn{1}{c}{ Sig. } \\
\hline Corrected Model & $32,873^{\mathrm{a}}$ &, 029 \\
Intercept & 40139,852 &, 000 \\
Kelas & 1,132 &, 572 \\
Jenis & 26,912 &, 007 \\
Kelas * Jenis & 3,540 &, 318 \\
Error & 422,054 & \\
Total & 40739,000 & \\
Corrected Total & 454,927 & \\
\hline
\end{tabular}

a. R Squared $=, 072$ (Adjusted R Squared $=, 049$ )

\section{PEMBAHASAN}

\section{Langkah-langkah Model Pembelajaran SAVI berbantuan Software Pengendali Client}

Tahapan model pembelajaran SAVI berbantuan Software Pengendali Client pada penelitian ini dapat dilihat pada gambar 1. Model pembelajaran SAVI ini dipilih karena menekankan pada keaktifan siswa di mana sampel yang dipilih merupakan siswa-siswa di jenjang sekolah dasar.

\section{Tahap persiapan (pendahuluan)}

Pada tahap persiapan, siswa dikondisikan untuk siap mengikuti pembelajaran. Kegiatan menyiapkan siswa meliputi menjawab salam pembuka, berdoa, memberi motivasi atau rangsang-

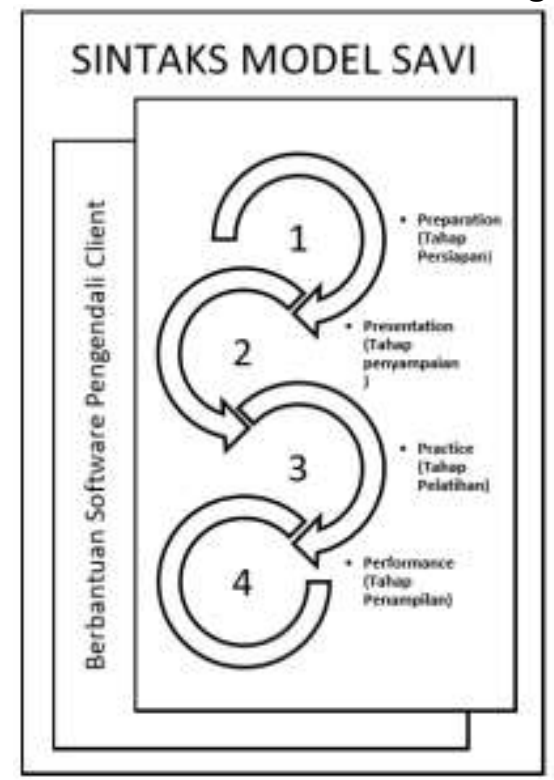

Gambar 1. Sintaks SAVI berbantuan Software Pengendali Client -an dan perasaan positif, menyampaikan tujuan pembelajaran serta mengarahkan siswa agar dapat terlibat aktif dalam proses pembelajaran. Beberapa kegiatan tersebut yaitu memberi motivasi atau rangsangan dan perasaan positif dan menyampaikan tujuan pembelajaran dilaksanakan guru dengan bantuan software pengendali client.

Dalam memberikan motivasi atau rangsangan dan perasaan positif dilakukan dengan beberapa cara antara lain mengajak untuk bermain, melihat gambar yang ada dalam presentasi serta menayangkan video. Model pembelajaran ini dapat disesuaikan dengan kondisi pembelajaran yang dinamis, sehingga kreativitas dan improvisasi peserta didik sangat dibutuhkan (Saraswati 2019). Caracara tersebut dilakukan oleh guru dengan bantuan software pengendali client sehingga membuat siswa dapat fokus pada komputer mereka masing-masing.

Tahap penyampaian (kegiatan inti)

Kegiatan selanjutnya yaitu siswa diberi kesempatan menganalisis (visual dan intellectual) gambar dan teks bacaan secara cermat yang menunjukkan situasi yang berkaitan dengan penyajian data tunggal. Dalam usaha untuk menganalisis ini dibutuhkan kemampuan siswa berpikir kritis. Model pembelajaran SAVI ini sangat cocok digunakan untuk mengasah kemampuan tersebut. Terbukti dalam penelitian Iskandar (2016) menunjukkan bahwa ada peningkatan kemampuan berpikir kritis siswa melalui model pembelajaran SAVI. Penerapan model SAVI berbantuan software pengendali client hanya bisa dilakukan di laboratorium komputer yang terkoneksi dalam satu jaringan. Pada tahap ini diharapkan guru dapat menemukan cara yang menarik untuk materi belajar yang baru dan cocok untuk semua gaya belajar siswa. Keaktifan guru diperlukan untuk mengoptimalkan belajar siswa secara utuh.

Tahap pelatihan (kegiatan inti)

Di tahap ini siswa mengerjakan LKS yang berkaitan dengan penyajian data tunggal dengan cara berdiskusi kelompok. Kemampuan intelektual siswa dibutuhkan pada saat 
kegiatan ini di mana mereka dituntut untuk bisa bekerja sama dalam kelompok. Siswa akan merasa lebih ringan dalam mengerjakan LKS jika dilakukan dengan bekerja sama dalam kelompok.

Dalam proses ini kemampuan somatic, auditory, visual dan intelektual siswa diperlukan dalam mempresentasikan hasil kerjanya. Kemampuan somatic siswa terlihat ketika siswa mengoperasikan komputer mereka masing-masing untuk mempresen-tasikan hasil kerja LKS. Kemampuan auditory siswa terlihat ketika siswa membaca dan mendengarkan hasil presentasi temannya. Kemampuan visual siswa terlihat ketika siswa memperhatikan presentasi temannya yang tersaji pada komputer mereka masing-masing. Kemampuan intelek-tual siswa terlihat ketika siswa memberikan respon berupa kritik dan saran terhadap hasil kerja LKS teman yang melakukan presentasi. Tugas guru dalam hal ini adalah membimbing dalam menerima kritik dan saran guna perbaikan hasil kerja LKS pada tiap kelompoknya.

Tahap penampilan hasil (kegiatan penutup)

Pada tahap ini siswa diberi penguatan oleh guru serta mendapatkan evaluasi, tugas rumah dan pesan belajar dari guru. Untuk mengetahui suatu proses pembelajaran berhasil atau tidak, guru sangat penting melakukan evaluasi. Menurut Suwandi dalam Rohmadheny \& Yudiari (2015) penilaian harus dilakukan guru untuk melihat keberhasilan siswa dalam suatu kegiatan pembelajaran. Pada tahap ini kembali guru menggunakan bantuan software pengendali client untuk memberikan penguatan, evaluasi, tugas rumah dan pesan belajar. (auditori, intelektual). Setelah pembelajaran diharapkan siswa mampu menerapkan dan memperluas pengetahuan atau keterampilan barunya yang berkaitan dengan penyajian data tunggal.

\section{Tingkat Kedisiplinan Siswa dalam Model Pembelajaran SAVI berbantuan Software Pengendali Client}

Menurut Ariananda et al. (2014) dalam proses pembentukan sikap siswa diperlukan kedisiplinan agar kelak siswa dapat sukses bukan hanya dalam belajar namun juga saat bekerja nanti. Hal ini menjadi sangat penting untuk dibentuk pada diri siswa maka diperlukan cara untuk membiasakan siswa bersikap disiplin. Selama proses pembelajaran menggunakan model pembelajaran ini guru mengamati tingkah laku siswa yang berorientasi pada tingkat kedisiplinannya. Menurut Naim (2012), disiplin adalah sikap tunduk dan patuh untuk melaksanakan keputusan, peraturan dan perintah yang berlaku. Tingkat kedisiplinan yang diamati guru terdiri dari aspek ketaatan terhadap tata tertib, ketaatan terhadap kegiatan belajar dan ketaatan dalam mengerjakan tugas.

Observasi tingkat kedisiplinan siswa dilakukan selama $5 x$ pertemuan di mana tiap pertemuan terdapat 2-3 observer. Untuk menjamin objektivitas dalam penilaian ini maka yang berperan sebagai observer 1 (01) adalah guru kelas VA dan VB, observer 2 (O2) adalah peneliti sendiri, observer 3 (O3) adalah Kepala Sekolah Sr. Veronique Marie SPM dan guru sejawat Fahmi Hidayatullah. Observasi tingkat kedisiplinan ini dilakukan terhadap kelas kontrol dan eksperimen. Hasil observasi terhadap ketiga aspek pada kelas kontrol berada pada kategori sedang sebaliknya hasil observasi pada kelas eksperimen berada pada kategori tinggi.

Dari hasil observasi tersebut, peneliti melanjutkan dengan uji Independent $T$ Test untuk mengetahui pengaruh model SAVI berbantuan software pengendali client terhadap tingkat kedisiplinan siswa. Dari hasil uji tersebut didapatkan bahwa terdapat perbedaan signifikan tingkat kedisiplinan belajar Matematika antara kedua kelompok kelas. Dengan kata lain model pembelajaran SAVI berbantuan software pengendali client mempunyai pengaruh terhadap tingkat kedisiplinan belajar Matematika siswa. 
Hasil Belajar Siswa dalam Model Pembelajaran SAVI berbantuan Software Pengendali Client

Menurut Achdiyat \& Andriyani (2016), hasil belajar domain kognitif siswa dapat dilihat dari skor pemberian tes setelah siswa mampu menyele-saikan suatu permasalahan dalam proses pembelajaran. Berdasarkan penelitian Puspitasari (2019) dan Sundari (2019), penerapan model SAVI berbantuan media terbukti bisa meningkatkan hasil belajar khususnya ranah kognitif. Selain itu menurut hasil penelitian Sugesti et al. (2018) model SAVI dinilai lebih baik daripada model pembelajaran langsung. Dalam model pembelajaran SAVI berbantuan software pengendali client ini, hasil belajar siswa didapatkan dari skor hasil pretest dan posttest pada kelas kontrol dan kelas eksperimen. Rata-rata skor hasil pretest pada kelas kontrol mencapai angka 17,30 sedangkan pada kelas eksperimen mencapai angka 17,83. Rata-rata skor hasil posttest pada kelas kontrol mencapai 18,57 sedangkan pada kelas eksperimen mencapai angka 18,42.

Berdasarkan skor hasil pretest dan posttest tersebut maka dilakukanlah uji ANOVA Two Way yang digunakan untuk mengetahui pengaruh penggunaan software pengendali client dalam model pembelajaran SAVI terhadap hasil belajar siswa. Nilai Sig. yang didapat dari hasil uji tersebut sebesar 0,572 >0,05 sehingga kesimpulan yang didapat adalah tidak terdapat perbedaan signifikan hasil belajar Matematika antara kelompok siswa kelas kontrol dan kelas eksperimen.

\section{SIMPULAN}

Empat tahap dalam model pembelajaran SAVI ini dilaksanakan guru dengan bantuan software pengendali client. Kesimpulan dari penelitian ini adalah model pembelajaran SAVI berbantuan software pengendali client mempunyai pengaruh yang signifikan terhadap tingkat kedisiplinan siswa ketika digunakan di laboratorium komputer. Model pembelajaran SAVI yang digunakan oleh kedua kelas memberikan dampak bahwa hasil belajar dari kedua kelas tidak ada perbedaan yang signifikan, dengan kata lain model SAVI sangat cocok untuk dimodifikasi dengan media pembelajaran yang lain karena model SAVI terbukti dapat meningkatkan hasil belajar siswa.

Beberapa rekomendasi yang dapat digunakan untuk para peneliti berikutnya, yaitu: 1) Proses penelitian ini tidak berlangsung secara sempurna di mana pertemuan ke-6 tidak bisa dilaksanakan dikarenakan pandemi Covid-19 yang melanda Indonesia, sehingga masih banyak kekurangan dalam penelitian ini. Dari hal tersebut diharapkan penelitian ini dapat dijadikan acuan serta rujukan selanjutnya untuk penelitian lebih mendalam; 2) Model pembelajaran SAVI berbantuan software pengendali client mampu mengontrol tingkat kedisiplinan siswa saat di kelas sehingga dapat dijadikan alternatif pembelajaran di sekolah khususnya ketika pembelajaran di laboratorium komputer; 3) sarana dan prasarana yang memadai (jumlah komputer yang harus sama dengan jumlah siswa di dalam kelas) sangat mendukung terlaksananya Model pembelajaran SAVI berbantuan software pengendali client; 4) Model pembelajaran SAVI berbantuan software pengendali client belum mempengaruhi hasil belajar Matematika siswa secara signifikan sehingga diperlukan penelitian yang mendalam terkait hal teknis mengenai penerapan model SAVI di laboratorium komputer.

\section{REFERENSI}

Abdulhak, I. (2015). Teknologi Keguruan. PT Remaja Rosdakarya.

Achdiyat, M., \& Andriyani, F. (2016). Hasil belajar matematika ditinjau dari model pembelajaran Teams Assisted Individualization (TAI). Formatif: Jurnal Ilmiah Pendidikan MIPA, 6(3), 246-255. https://doi.org/http://dx.doi.org/10.3099 8/formatif.v6i3.996 
Akhtar, S., Warburton, S., \& Xu, W. (2017). The use of an online learning and teaching system for monitoring computer aided design student participation and predicting student success. International Journal of Technology and Design Education, 27(2), 251-270. https://doi.org/https://doi.org/10.10 07/s10798-015-9346-8

Ariananda, E. S., Hasan, S., \& Rakhman, M. (2014). Pengaruh kedisiplinan siswa di sekolah terhadap prestasi belajar siswa teknik pendingin. Journal of Mechanical Engineering Education, 1(2), 233-238. https://doi.org/https://doi.org/10.17 509/jmee.v1i2.3805

Carrasco, M. R., \& Torrecilla, F. J. M. (2012). Learning environments with technological resources: a look at their contribution to student performance in Latin American elementary schools. Educational Technology Research and Development, 60(6), 1107-1128. https://doi.org/https://doi.org/10.10 07/s11423-012-9262-5

Cemara, G. A. G., \& Sudana, D. N. (2019). Pengaruh Model Pembelajaran SAVI Bermuatan Peta Pikiran Terhadap Kreativitas dan Penguasaan Kompetensi Pengetahuan IPA Siswa. Jurnal IImiah Sekolah Dasar, 3(3), 351-360.

https://doi.org/http://dx.doi.org/10. 23887/jisd.v3i3.18895

Fabian, K., Topping, K. J., \& Barron, I. G. (2018). Using mobile technologies for mathematics: effects on student attitudes and achievement. Educational Technology Research and Development, 66(5), 1119-1139. https://doi.org/https://doi.org/10.10 07/s11423-018-9580-3

Gaol, H. A. L. (2014). The Effect of Applying Somatic Auditory Visual Intellectual (Savi) Method on
Students'achievement in Writing Report Text. TRANSFORM Journal of English Language Teaching and Learning of FBS UNIMED, 3(4), 1-17.

Harron, N. A., Saod, A. H. M., Ramlan, S. A., Abd Razak, F., Ishak, N. H., Sadimin, S., Rashid, A. N. A., \& Ismail, N. (2017). ComTrack: Implementation of innovative computer lab management tool for academic institutions. 2017 IEEE Symposium on Computer Applications \& Industrial Electronics (ISCAIE), 132-135. https://doi.org/10.1109/ISCAIE.2017.807 4964

Mangesti, T. (2016). Pengembangan Instrumen Penilaian Sikap Disiplin Pada Pembelajaran Bahasa Prancis Tingkat SMA Kelas X SMAN 2 Magelang.

Matuk, C. F., Linn, M. C., \& Eylon, B.-S. (2015). Technology to support teachers using evidence from student work to customize technology-enhanced inquiry units. Instructional Science, 43(2), 229-257. https://doi.org/https://doi.org/10.1007/s 11251-014-9338-1

Naim, N. (2012). Character Building. AR. Ruzzmedia.

Praherdhiono, H., Setyosari, P., Degeng, I. N. S., Slamet, T. I., Surahman, E., Adi, E. P., Degeng, M. D. K., \& Abidin, Z. (2019). Teori dan Implementasi Teknologi Pendidikan: Era Belajar Abad 21 dan Revolusi Industri 4.0. Seribu Bintang.

Puspitasari, A. (2019). Pengaruh Model Pembelajaran SAVI (Somatic, Auditory, Visualization, Intellectual) dengan Media Hide dan Seek Puzzle Terhadap Hasil Belajar IPA. Universitas Muhammadiyah Magelang. http://eprintslib.ummgl.ac.id/id/eprint/6 1

Rohmadheny, P. S., \& Yudiari, N. (2015). Peduli Lingkungan melalui Kontinuitas Pembiasaan Perilaku Buang Sampah pada Tempatnya. PROSIDING SEMINAR NASIONAL "Optimalisasi Active Learning Dan Character Building Dalam Meningkatkan Daya Saing Bangsa Di Era 
Masyarakat Ekonomi Asean (MEA), 45-49.

https://doi.org/http://dx.doi.org/10. 23887/jjpgsd.v3i1.5683

Rücker, M. T., \& Pinkwart, N. (2016). Review and discussion of children's conceptions of computers. Journal of Science Education and Technology, 25(2), 274-283. https://doi.org/https://doi.org/10.10 07/s10956-015-9592-2

Salvi, A., Konde, R., Karlenaik, P., \& Jambhale, S. (2019). An Automated Approach to Supervising and Controlling of Computer Laboratory over LAN. 2019 IEEE 5th International Conference for Convergence in Technology (I2CT), 1-4. https://doi.org/10.1109/I2CT45611. 2019.9033596

Sarnoko, S., Ruminiati, R., \& Setyosari, P. (2016). Penerapan pendekatan SAVI berbantuan video pembelajaran untuk meningkatkan aktivitas dan hasil belajar IPS siswa kelas IV SDN I Sanan Girimarto Wonogiri. Jurnal Pendidikan: Teori, Penelitian, Dan Pengembangan, 1(7), 1235-1241. https://doi.org/http://dx.doi.org/10. 17977/jp.v1i7.6524

Schoenfeld, A. H. (2013). Classroom observations in theory and practice. ZDM, 45(4), 607-621. https://doi.org/https://doi.org/10.10 07/s11858-012-0483-1

Shoimin, A. (2013). model pembelajaran inovatif dalam kurikulum 2013. Ar-Ruzz Media.

Sohail, S., Felemban, E., AlThobaiti, B., \& AlHetairshi, A. (2011). Smart-Lab, LAN Based Application for Effective Lab Supervision. 2011 Second International Conference on Networking and Distributed Computing, 15-19. https://doi.org/10.1109/ICNDC.2011.11

Sugesti, I. J., Simamora, R., \& Yarmayani, A. (2018). Perbandingan Kemampuan Pemecahan Masalah Matematis Menggunakan Model Pembelajaran Savi Dan Model Pembelajaran Langsung Siswa Kelas Viii SMPN 2 Kuala Tungkal. PHI: Jurnal Pendidikan Matematika, 2(1), 1422.

https://doi.org/http://dx.doi.org/10.3308 7/phi.v2i1.22

Sugiyono. (2015). Metode Penelitian Kuantitatif, Kualitatif dan R\&D. Penerbit Alfabeta.

file://C:/Users/HP/AppData/Local/Mend eley Ltd./Mendeley Desktop/Downloaded/Sugiyono - 2015 Metode Penelitian Kuantitatif, Kualitatif dan R\&D.pdf

Sundari, S. (2019). Meningkatkan hasil belajar siswa dalam pembelajaran matematika melalui pendekatan savi pada siswa kelas VB SDIT al-Izzah Sorong. Qalam: Jurnal IImu Kependidikan, 5(2), 44-51. https://doi.org/https://doi.org/10.33506 /jq.v5i2.260

Yaumi, M. (2018). Media dan teknologi pembelajaran. Prenada Media. 